\title{
Ulysse, 1982, de Agnès Varda. Breve estudio acerca de la temporalidad de un cortometraje sobre una fotografía
}

\section{Ulysse, 1982, by Agnès Varda. Brief Study on the Temporality of a Short Film About a Photograph}

\author{
María Eugenia Rabadán Villalpando ${ }^{a}$
}

\begin{abstract}
:
This work tries to analyze Ulysse, 1982, by Agnès Varda: a short film about a photograph taken by the same author on a beach in La Mancha twenty-eight years ago to an Egyptian man, a child, and a dead goat. The analysis takes place in the field of visual arts studies. Particularly in the tradition of theories on temporality in the analysis of works. This tradition, which forms the warp and weft of this work, refers to authors such as George Kubler, George Didi-Huberman, Alexander Nagel, Christopher Wood, and Thomas Kuhn, among others. The central theme of Ulysse - as the author has also declared - in addition to the question of memory and time, is the relationship of memory and representation in the image. How can memory be represented in the moving image superimposed on the still image? How does filming include the complex framework of previous times, constantly updated, projected into the future, simultaneous, parallel, coexisting in the short film? I try, therefore, to examine these different temporalities contained in Ulysse, and the sense of plasticity that shapes Agnès Varda's work.
\end{abstract}

\section{Keywords:}

Agnès Varda, temporalities in cinematography, temporalities in photography, cinecriture, cinematography creates the real

\section{Resumen:}

Este trabajo trata de analizar Ulysse, 1982, de Agnès Varda: un cortometraje sobre una fotografía tomada por la misma autora en una playa de La Mancha veintiocho años atrás a un hombre egipcio, a un niño, y a una cabra muerta. El análisis tiene lugar en el ámbito de los estudios sobre artes visuales. Particularmente, en la tradición de teorías sobre la temporalidad en el análisis de las obras. Esta tradición, que forma la trama y urdimbre de este trabajo, refiere autores como George Kubler, George Didi-Huberman, Alexander Nagel, Christopher Wood, y Thomas Kuhn entre otros. El tema central de Ulysse -como también lo ha declarado la autora- además de la cuestión de la memoria y el tiempo, es la relación de la memoria y la representación en la imagen. ¿Cómo la memoria puede ser representada en la imagen en movimiento sobrepuesta a la imagen fija? ¿Cómo la filmación incluye el complejo entramado de tiempos anteriores, en constante actualización, proyectados a futuro, simultáneos, paralelos, coexistentes en el cortometraje? Intento, por tanto, examinar estas diferentes temporalidades contenidas en Ulysse, y el sentido de la plasticidad que da forma al trabajo de Agnès Varda.

\section{Palabras Clave:}

Agnès Varda, temporalidades en cinematografía, temporalidades en fotografía cinecriture, cinematografía crea lo real

\section{Introducción}

Lo que me interesaba -afirma Agnès Varda- no era solo la cuestión de mi memoria y tiempo, sino la cuestión de la imagen misma, la representación de la memoria, cuestionar la relación entre memoria y representación. Y eso es lo que trata el cine: una reexaminación del tiempo, el movimiento y especialmente la imagen. Al explorar en esta imagen, he encontrado a la gente que ha servido como sus modelos (jahora veintiocho años más viejos!) he aprendido acerca del día y representaciones del día en que la tomé -por ejemplo, que hubo en la televisión ese día, qué había en las noticias ese día- reintroduciendo el movimiento en la imagen que yo fijé, era el cine que redescubrí y re-examiné. Aparte de mi falta de memoria de ese día emergió esta imagen, que fue una fotografía que de alguna manera resistió todos mis intentos de analizarla y toda mi investigación en ella. [...] A través de una combinación de referencias, memorias y asociaciones libres, cada película me involucra en las exploraciones de temas que me parecen ser raramente tratados en el cine. 1

Ulysse (1982) de Agnès Varda, es un cortometraje acerca de una fotografía que la propia cineasta había tomado con una cámara de placas al borde del mar, en una playa rocosa de 
La Mancha, hacía veintiocho años, a un niño -llamado Ulises-, un hombre egipcio y una cabra muerta (Varda, 1982). La fotografía muestra al hombre desnudo de pie, de espaldas a la cámara arriba a la izquierda, al niño sentado en la playa a la derecha del hombre, y a la cabra muerta a la derecha abajo yacente en la playa rocosa; al fondo muy arriba se ve la línea costera y por encima el mar. Al ser ésta una imagen tomada con una cámara de placas, en el vidrio se imprime una imagen doblemente invertida. 2

El cortometraje, dirigido y cinescrito por Agnès Varda, fue filmado en blanco y negro todo el cuerpo de fotografías y las tomas televisivas del 9 de mayo de 1954; en color las pinturas, las tomas de los años ochenta. Tiene una duración de 21 '.

El tema central de la obra es, en términos de Varda, según cito en el epígrafe y parafraseándola, la representación de la memoria en la imagen y la cuestión de memoria y tiempo, que finalmente es la definición del cine. En ese sentido trato de analizar, con base en la obra de Alexander Nagel y Christopher Wood, la pluralidad temporal y su plasticidad en Ulysse según he visualizado el tiempo antes de la fotografía, 1954; el tiempo presente que actualiza la imagen cada vez que vemos el cortometraje; la sobrevivencia de la fotografía como de la filmación que sobrepasará nuestra existencia proyecta un tiempo a futuro; el tiempo simultáneo con la integración de las imágenes de lo sucedido el día y la hora en que fue tomada la fotografía de La Mancha; el tiempo paralelo a lo real según el método de trabajo de Agnès Varda, todo lo cual coexiste en este cortometraje. 3

Agnès Varda fue además de fotógrafa, cineasta, y escritora de sus propios guiones cinematográficos, historiadora del arte. En consecuencia, el cortometraje revela la presencia de esta disciplina y algunas de sus metodologías como la iconografía relativa a lo simbólico en la cabra muerta, la formación del contexto en relación con otras obras de arte, el contraste de la verosimilitud de la fotografía y el cine, con la pintura y escultura, y el análisis del tiempo. Su filmografía muestra otros estudios cinematográficos sobre imágenes fijas fotográficas o pictóricas que igualmente cuestionan la pluralidad temporal en la imagen y la relación entre el tiempo y representación. Me refiero a Daguerréotypes [Daguerrotipos] (1874), Des glaneuses [Las espigadoras] (1857) de Jean-François Millet, del Museé d' Orsay en París, en la película Les Glaneurs y la Glaneuse [Los espigadores y la espigadora] (2000), o Mur Murs (1980) que trata muralismo en Los Angeles, California; después de todo ella había estudiado historia del arte en la Ecole du Louvre. 4

\section{Temporalidades en Ulysse}

Con anterioridad a Ulysee -el cortometraje- hay un tiempo de veintiocho años, desde que fue tomada la fotografía de La Mancha hasta el rodaje. $Y$ hay un tiempo anterior a la imagen fija creada en La Mancha, desde que Ulises nace en
Denia, enferma de una coxa plana y, debido a ello, requiere de bañarse en el mar y masajes con algas mojadas; desde que un hombre nacido en Alejandría viaja hasta La Mancha no sabemos en qué circunstancias; desde que una cabra nace en St. Aubin-sur-Mer hasta que muere en esa playa. $Y$ hay temporalidades fuera de este cuadro fotográfico en particular, aunque no de otras imágenes fotográficas que aparecerán en la filmación, desde que Agnès Varda habita en las calles Daguerre y Nadar, enseguida de la familia Llorca a la que pertenece Ulises; y desde que esta familia de republicanos españoles se refugia en Francia. Todo ello es un flujo de distintas temporalidades convergentes en La Mancha para la toma fotográfica del 9 de mayo de 1954.

El tiempo anterior al rodaje, el que fundamentalmente va a cuestionar la representación de la memoria en la imagen cinematográfica, se extiende durante veintiocho años. Es el tiempo necesario de espera para menguar en lo real la memoria de todos los personajes en el cortometraje. Mientras el padre de Ulises Llorca parece haber desaparecido de la escena en alguna forma, pero la imagen fotográfica le sobrevive: una temporalidad de la imagen analizada por Roland Barthes o John Berger entre otros autores. Didi-Huberman afirma que la imagen sólo puede ser pensable en una construcción de la memoria; John Berger, por otra parte, al reflexionar sobre la reproducción de pinturas en el cine, piensa que éstas se convierten en material para el argumento del realizador. 5-7

He mencionado que del cortometraje fue filmado en blanco y negro el cuerpo de fotografías y las tomas televisivas del 9 de mayo de 1954 -la imagen en televisor a color data de 1968 según Regis Debray-; y en color las pinturas, las tomas cinematográficas de los años ochenta. Esto implica una concepción occidental y tecnológica del tiempo en que lo antiguo es blanco y negro y en color el avance tecnológico. También significa, por otra parte, que el fenómeno artístico no desecha su pasado. 8

Al conjunto simbólico derivado de lo terrenal en Ulises y una cabra en una playa rocosa de La Mancha, Varda en el cortometraje lo eleva a temporalidades mitológicas. Ulises a la orilla del mar, del mar Mediterráneo; y la cabra como un signo del zodíaco entre meteoros, o la cabra Almatea que alimenta a Zeus.

El tiempo de diversos sucesos aconteciendo simultáneamente en diferentes sitios al momento en que sucede la toma fotográfica de La Mancha, Agnès Varda lo presenta en una secuencia que muestra la derrota francesa en Dien Bien Phu y el luto que guardaban los franceses. El cierre de la ópera y los teatros nacionales. El silencio en la radio y la televisión. Imágenes intertextuales de la televisión se integran en el cortometraje: el silencio de Charles De Gaulle, bajo el arco del triunfo, ante la llama al soldado desconocido. El Gorila y el Gato Magot. La muerte de Gabrielle Colette, la escritora feminista -había sucedido 
cinco días antes de la toma de la fotografía de La Manchay otras referencias a Sylvie Vartan, Yvonne Printemps, Yves Montand y Edit Piaf, aparecidas en la televisión el 8 de agosto de 1954. La Conferencia de Génova de ese año, que reunió a representantes del Viet-Minh, los Estados Unidos, la Unión Soviética, el Reino Unido, e Indochina, para tratar tópicos de la Guerra de Corea, de la de Indochina y temas de Viet Nam. Estas imágenes son documentación recabada por Agnès Varda: no vienen de su memoria de acuerdo con el parlamento del cortometraje. Su función como cineasta no obstante que ha trabajado en investigación- es hacer la obra de arte, no hacer una comprobación propiamente histórica. El sentido que las imágenes fotográficas y televisivas tienen en esta obra es el de rememorar lo acontecido el día de la toma de la fotografía de Ulises que, según la concepción cinematográfica de Agnès Varda, probablemente, sea paralela a lo real.

Por otra parte, Varda formó parte de la comunidad en torno a Cahiers de Cinema: la publicación francesa sobre cine editada por Andre Bazin y Henry Langlois. La mayor parte de los cineastas de este círculo constituyó la Nouvelle vague francesa -el movimiento cinematográfico de mediados del siglo pasado, formado por Alain Resnais, Jean-Luc Godard, Francois Trouffaut, Claude Chabrol, Jacques Rivette y Eric Rohmer-. En ese sentido podríamos considerar la concepción de esta tendencia como George Kubler aborda la categoría de estilo en términos de su temporalidad, digamos de ciclo biológico (2013, pág. 18) y también la noción de comunidad artística según la comunidad científica de Thomas Kuhn en el ámbito de la articulación paradigmática. 9-10

Esta comunidad de cineastas consideró de manera conceptual el lenguaje propiamente cinematográfico como tema de la filmación -de ahí que se pueda rodar una película sobre una imagen fija-. De igual manera dan término a una tradición en la cual el autor solía ilustrar textos literarios y, al mismo tiempo, articulan un nuevo paradigma en el cual se escriben guiones sobre el lenguaje cinematográfico -un fenómeno autonómico que en artes visuales había comenzado a suceder entre los pintores impresionistas y postimpresionistas- y Agnès Varda contribuye con esta práctica al escribir y dirigir sus propias películas. Por ello en Ulysse ella entiende la obra como un episodio relativo a la representación de la memoria en la imagen, al tiempo de definir de esta forma el cine.

Varda pensó el transcurso de los veintiocho años -desde que tomó la fotografía inicial en La Mancha hasta la filmación del cortometraje- como la materia prima de Ulysse. El paso del tiempo había puesto en escena a la memoria en la mente de la comunidad alrededor del episodio en La Mancha. Era un tema que no podía pasar por alto una cineasta de la

\footnotetext{
* Tema: Un fotógrafo amateur y dos de sus amigos comentan una selección de fotos tomadas un poco por todas partes en el mundo.
}

Nouvele vague. Agnès Varda no puede salirse de su época y rueda, por tanto, Ulysse, a fin de reflexionar sobre la naturaleza de la cinematografía. Cléo de 5 a 7 , es un largometraje en el cual Varda había considerado el transcurso del tiempo real en la edición. Había medido el tiempo de cada paso que Cléo da a lo largo de la película, y es posible ver, si se desea, la proyección de la cinta, por la tarde, precisamente de 5 a 7 , de forma equivalente a como la protagonista había caminado en la ciudad. 11

El contexto para estudiar Ulysse, con relación a la tradición de obras de la Nouvelle vague del cine francés sobre imágenes pictóricas y fotográficas incluye los siguientes cortometrajes: Van Gogh (1948); Guernica (1950); Nuit et Bruillard [Noche y niebla] (1955) de Alain Resnais -quien fue editor de la primera obra de Agnès Varda, La Pointe Courte (1956)-; Le Mystère Picasso [EI misterio Picasso] (1956) de Henri Georges Clouzot; La Jetée [El embarcadero] (1962) o $\mathrm{Si}$ j'avais quatre dromedaires [Si yo tuviera cuatro dromedarios] (1966) de Chris Marker.

La primera imagen de esta última obra, luego de la dedicatoria a Machenka, comienza citando conceptualmente- un segmento de su guion cinematográfico, lo que trae a la mente el cine silente, también porque, paradójicamente, está sonorizado con una pieza para piano y, literalmente, dice:

\section{Sujet:}

Un photographe amateur et deux de ses amis commentent un choix de photos prises un peu partout dans le monde.

A diferencia de Ulysse para el que Varda escribió un guion original, la película de Marker se hizo a partir de Le Bestiaire ou Cortège D'Orphée [El bestiario o cortejo de Orfeo], de Guillaume Apollinaire, cuya portada aparece al pasar al tercer plano. Las secuencias son filmaciones del poema y de las imágenes fotográficas. Estos recursos, entre otros, conforman el lenguaje cinematográfico: la imagen en movimiento en primer lugar, después la edición, el sonido, la narrativa... Chris Marker trabajó en la producción de Salut les cubains (1963) el cortometraje de Agnès Varda en el cual emplearon los recursos fotográficos como Marker lo había hecho previamente en La Jetèe y luego lo hará en Si j'avais quatre dromedaires. Susan Sontag menciona en On photography el uso de la fotografía en la imagen cinematográfica de Marker. Todo ello forma la tradición del cortometraje francés de esos años, en la cual se inscribe Ulysse. "Esta es la historia de un hombre, marcado por una imagen de su niñez -introduce Marker en el diálogo de La Jetée-." 
Esto hace posible conjeturar que Varda, influida por La Jetèe, hubiera decidido -a partir de la imagen fotográfica de Ulises y las fotografías del viaje a La Mancha- hacer otra película sobre representación del olvido en dichas fotografías dentro del cortometraje sobre un niño que algún día habría de transformarse en un hombre -Ulises en 1982; o que la idea de Ulysse estaba en la mente de ambos: Agnès Varda y Chris Marker. Planteo este supuesto considerando principalmente dos aspectos que aparecen en la película: la fotografía de Ulises había sido tomada ocho años antes de que se filmara La Jetée. En Ulysse se filma también la pintura sobre papel, que es una copia de la fotografía, con la cual el niño deja testimonio de haber visto su imagen de la infancia en la playa rocosa junto al egipcio y la cabra muerta, lo cual pudo haber sido motivado por Agnès Varda para un posible rodaje ulterior, una segunda convergencia temporal. Es decir que Varda pudo haber dado la fotografía de La Mancha a Ulises para que dibujase el testimonio, y después esperar más de dos décadas a que, en realidad, la memoria y el olvido maduraran para consolidar el guion sobre el cual se filmaría el cortometraje. En otros términos: el cine crea lo real. Después de todo esta cineasta francesa ha declarado que los dos matices de la realidad que le interesan son: por una parte, el aspecto muy premeditado y reconstruido, el documental, la vida real y, por otra, las cosas capturadas en el momento.

Finalmente, otro de los tiempos del cortometraje es el que pone en acto todo lo filmado cada vez que se proyecta el cortometraje. Nunca ha sido visto el cortometraje como lo vemos en lo actual. El tiempo del rodaje es, a su vez, el tiempo de poner en acto la fotografía. $Y$ de conjugar todos estos tiempos en una cinta. De hacerlos converger. La filmación de Ulysse tiene el fin de actualizar la fotografía de La Mancha, pero también de que en cada proyección del cortometraje sea actualizada por los observadores. Después de todo, la creación de esta obra fue una obra encarnada en la autobiografía de Agnès Varda: "Pienso - dice Varda- que mis filmes son todos autobiográficos. Ulises es completamente: hay aún fotos mostrándome y a ese niño Ulises [...]" (Wera, 2014, pág. 119) Cada parte de su vida actualizaba esta obra, que finalmente sobrevive al tiempo de Agnès Varda. 12

\section{Conclusiones}

Este ensayo ha estudiado visualmente el cortometraje Ulysse, 1982, de Agnès Varda, en función de analizar la conjugación de temporalidades que estructuran la obra. El ensayo fundamenta el estudio de la composición de las temporalidades dado que el tema central de Ulysse según Varda, es la relación de la memoria y la representación en la imagen, lo que es, según la autora, su concepción de cine.

Este cortometraje es particularmente interesante para analizar diferentes temporalidades por la amalgama de historia del arte, fotografía y cinematografía que reúne la autora en su formación y que se objetiva en su obra.
Temporalidades de antecedentes, actualizaciones y proyecciones a futuro. Sucesos ocurridos simultáneamente a la toma de la fotografía en 1954 y que soportan la construcción de la memoria en la comunidad de personajes en la filmación. Tiempos mitológicos, metahistóricos. Tiempos de las distintas disciplinas pictórica, fotográfica, cinematográfica. Tiempos desde la perspectiva de las tecnologías. Tiempos todos ellos narrados en el argumento escrito por Agnès Varda como obra, no como análisis según lo hace este ensayo.

El argumento de Ulysse no explica el tiempo ni el movimiento porque lo hacen las imágenes, quizá como Rudolf Arnheim expone en Arte y Percepción Visual el supuesto de la imposibilidad de explicar cosas visuales mediante el lenguaje verbal. En ese sentido es imperativo observar el cortometraje al tiempo de conocer la visibilidad del lenguaje cinematográfico y el tejido de temporalidades que estructura a la obra. 13

\section{Referencias}

[1] Wera, F. "Interview with Agnès Varda". En K. T. Jefferson, Agnès Varda: Interviews. Estados Unidos de América: University Press of Mississippi / Jackson; 2014: 118-119.

[2] Varda, A. (1982). Ulysse. Recuperado el 19 de Agosto de 2021, de Vimeo: https://vimeo.com/402336189

[3] Nagel, A., \& Wood, C. The Plural Temporality of the Work of Art. En A. Groom, Time. Londres, Cambridge MA: Whitechapel Gallery; The MIT Press; 2013.

[4] Singh, A. (3 de Noviembre de 2013). YouTube. Recuperado el 5 de Agosto de 2014, de https://www.youtube.com/watch?v=wAv7-2v3TNk

[5] Barthes, R. La cámara lúcida. Barcelona, Buenos Aires, México: Paidós; 1999.

[6] Berger, J. Modos de ver. Barcelona: Gustavo Gili; 1980.

[7] Didi-Huberman, G. Before the image, Before time: The Sovereignity of Anachronism. En A. Groom, Time (págs. 34-37). Londres, Cambridge, Massachusetts: Whitechapel Gallery; The MIT Press; 2013: 35.

[8] Debray, R. Vida y muerte de la imagen. Hisoria de la mirada en Occidente. Barcelona: Paidos; 2000: 231.

[9] Kubler, G. The Shape of Time. En A. Groom, Time. Nueva York; Cambridge, MA: Whitechapel Gallery; 2013: 18.

[10] Kuhn, T. La estructura de las revoluciones cientificas. México: Fondo de Cultura Económica; 1995.

[11] Singh, A. (3 de Noviembre de 2013). YouTube. Recuperado el 5 de Agosto de 2014, de https://www.youtube.com/watch?v=wAv7-2v3TNk

[12] Wera, F. "Interview with Agnès Varda". En K. (. T. Jefferson, Agnès Varda: Interviews. Estados Unidos de América: University Press of Mississippi / Jackson; 2014: 119.

[13] Arnheim, R. Arte y percepción visual. Madrid: Alianza; 1981: 14 
Publicación semestral, Magotzi Boletín Cientifico de Artes del IA, Vol. 10, No. 19 (2022) 66-70 